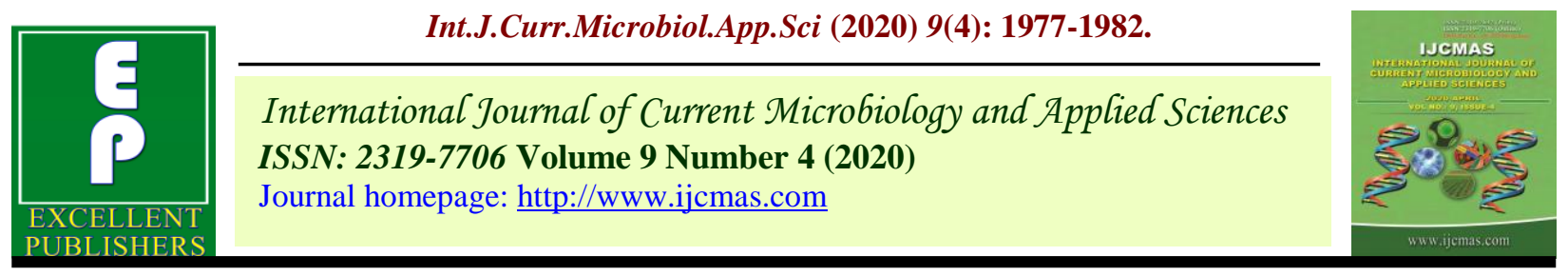

Original Research Article

https://doi.org/10.20546/ijcmas.2020.904.236

\title{
Energy Partitioning and Performance of Male Buffalo Calves Fed Ajwain Seed (Trachyspermum ammi) as Feed Additive
}

\author{
Kundan Kumar*, V. B. Chaturvedi, Vipin and Pramod Kumar Soni \\ Animal Nutrition, Division of Animal Nutrition, ICAR-Indian Veterinary Research \\ Institute, Izatnagar, U.P., India-243122, India \\ *Corresponding author
}

Keywords

Ajwain,

Additives,

Buffaloes,

Respiration, Rumen

Article Info

Accepted:

15 March 2020

Available Online:

10 April 2020

\section{A B S T R A C T}

The present experiment was aimed to study the effect of ajwain seeds (Trachyspermum ammi) as feed additive on energy partitioning and performance in male buffaloes.15 animals were divided and assigned to three treatments viz., T1 (control) animals were fed basal diet without additive, T2 and T3 were fed basal diet with ajwain @ 1 and 2\% DMI. The basal diet consisting of wheat straw and concentrate mixture in 50:50 ratio. The intake of gross energy (GE, MJ/d), digestible energy (DE, MJ/d), metabolizable energy (ME, MJ/d), as well as energy losses in the form of faeces, urine, methane, heat production (HP), and net energy (NE) were measured. Faecal output was measured in apparent digestibility trial. Heat and methane production were measured in an open circuit respiration chamber. The intake of GE, DE, and ME of the animals receiving ajwain @ 1 and $2 \%$ DMI showed no differences $(\mathrm{P}>0.05)$ from the control. The methane emission in terms of $1 / \mathrm{d}$ and $1 / \mathrm{kg}$ DMI were comparable in all the groups, whereas, in terms of $1 / \mathrm{kg}$ DDMI it was reduced by $18 \%(\mathrm{P}=0.029)$ in $\mathrm{T}_{3}$ as compared to $\mathrm{T}_{1}$. It can be concluded that dietary supplementation of ajwain did not have any significant impact on energy metabolism in buffaloes.

\section{Introduction}

The long drawn interest of researchers towards energy partitioning process consists of evaluating the amount of energy ingested by the animal and quantifying the loss of this energy during metabolism. Research has shown that for ruminants between 6 and 12\% of gross energy (GE) intake is lost in the form of methane. Livestock forms a major anthropogenic source of $\mathrm{CH}_{4}$ emission from the agriculture sector. Globally, livestock accounts for $\sim 37 \%$ of anthropogenic $\mathrm{CH}_{4}$ which is largely produced by enteric fermentation in ruminants as part of their normal digestive processes (FAO, 2006).

Need for safe and sustainable strategies for efficient utilization of feed in ruminants has brought to front use of plant extracts rich in phytochemicals as natural feed additives to modify the rumen fermentation and to 
decrease various losses. These inhibition properties of different PSM against a particular group of microbes can be exploited to reduce undesirable microbes in the rumen. The ajwain seed used in the present study contain $2-4 \%$ brown oil having active factor thymol $(50 \%)$ with germicidal, carminative and laxative property. Several in vitro studies have suggested that the effect of thymol (active principle of ajwain) is diet and $\mathrm{pH}$ dependent (Castillejos et al., 2006). Ajwain seeds are otherwise very popular in human kitchen as it is one of the major spices of Indian culinary. Thus, a study is proposed to assess the effect of adding T. ammi seeds as feed additive to describe the energy partitioning in male buffaloes.

\section{Materials and Methods}

The experiments were conducted in the sheds of Animal Nutrition Division, Indian Veterinary Research Institute, Izatnagar. The animal experimental protocol was approved by the Institutional Animal Ethics Committee (IAEC) and carried out as per the guidelines of Committee for the Purpose of Control and Supervision of Experiments in Animals (CPCSEA), Ministry of Environment, Forests and Climate Change, Government of India.

\section{Experimental protocol}

To study the effect of feed additive on animal performance, fifteen growing male buffaloes (Bubalus bubalis) of average body weight of $260 \mathrm{Kg}$ were used. Prior to initiation of the experimental trial, animals were treated for ecto and endo-parasites as per the standard protocol. All the animals were fed as per ICAR (2013). Roughage and concentrate mixture were offered in 50:50 ratio. The composition of concentrate mixture was maize $28 \%$, solvent extracted soybean meal $10 \%$, wheat bran $59 \%$, mineral mixture $2 \%$ and salt $1 \%$. To meet the vitamin requirement,
$5 \mathrm{~kg}$ chopped green maize per animal was provided twice in a week. The animals were divided into three groups of five animals each and were assigned to three treatments viz., T1 (control) animals were fed basal diet without additive, T2 and T3 were fed basal diet with ajwain @ 1 and 2\% DMI. The animals had access to clean drinking water throughout the experiment

\section{Metabolism trial}

A metabolism trial of 8 days duration including, 2 days adaptation in metabolic cages followed by 6 days collection was conducted after 30 days of experimental feeding to evaluate the effect of feeding ajwain as feed additive on nutrient utilization. Feed offered, residue, feces and urine were collected individually daily. After measuring the total amount, representative samples of residual feed, feces and urine were preserved for analysis.

\section{Chemical analyses}

The samples of feed offered, residual feed and faeces were analyzed for dry matter, ash, organic matter $(\mathrm{OM})$, crude protein $(\mathrm{CP})$ $(\mathrm{N} \times 6.25)$, and ether extract (EE) as per AOAC (1995). Neutral detergent fibre (NDF; estimated without amylase and sodium sulphite and expressed inclusive of the ash content), acid detergent fibre (ADF; also inclusive of ash content) were analyzed as per Van Soest et al., (1991). Nitrogen balance was calculated by estimating nitrogen in feed offered, residual feed, faeces and urine.

\section{Methane estimation}

Methane emissions were estimated by shifting the animals in open circuit respiration chamber. After two days of acclimatization, methane emissions were recorded for two consecutive days. 
The chamber was maintained at $25^{\circ} \mathrm{C}$ and $65 \%$ relative humidity with air flow rate of about $250 \mathrm{~L} / \mathrm{min}$. Methane was measured in air going in and coming out of the chamber through an infrared gas analyzer (Model 300, Analytical Development Co. Ltd., Hoddesdon, England).

\section{Calculations}

Energy partitioning was determined by subtracting the energy losses in the faeces, urine, methane, and the daily heat production from the GE intake. The DE was determined by subtracting energy losses in form of feces from GE. The ME was determined by subtracting energy losses in form of methane and urine from DE. The daily heat production of the animals was determined using the equation proposed by Brouwer (1965)

$$
\begin{aligned}
& \mathrm{HP}(\mathrm{kJ})=16.18 \quad \mathrm{O}_{2}+5.02 \quad \mathrm{CO}_{2}-2.17 \\
& \mathrm{CH}_{4}-5.99 \mathrm{~N} .
\end{aligned}
$$

Where $\mathrm{O}_{2}$ is the volume of consumed $\mathrm{O}_{2}(\mathrm{~L} / \mathrm{d}), \mathrm{CO}_{2}$ is the volume of produced $\mathrm{CO}_{2}(\mathrm{~L} / \mathrm{d}), \mathrm{CH}_{4}$ is the volume of produced $\mathrm{CH}_{4}(\mathrm{~L} / \mathrm{d})$, and $\mathrm{N}$ the amount of nitrogen excreted in the urine $(\mathrm{g} / \mathrm{d})$. net energy $(\mathrm{NE})$ was obtained by subtracting HP from MEI

\section{Statistical analysis}

The statistical analyses were performed as per standard methods by using SPSS computer package. The means were compared using Tukey's test if the main effect was significant $(\mathrm{P}<0.05)$ as per SPSS 16.0

\section{Results and Discussion}

The chemical composition of the concentrate mixture, wheat straw and ajwain seeds used for the feeding of the buffalo calves is given in Table 1. The concentrate mixture, wheat straw and ajwain contained 15.80, 2.53 and
14.9\% CP, respectively. The faecal energy, urinary energy and methane energy losses were not affected due to feeding of any additives Table 2 . There was no difference in the GE intake, faecal and urinary loss and digestible, metabolizable and net energy among the groups. There was non-significant difference in methane loss as \% of GE and net energy retention, T2 and T3 groups, respectively. The net energy retention in $\mathrm{T} 1$, T2 and T3 groups indicated no influence of ajwain on the energy balance. Similar results were reported by Samal et al., (2016) that faecal energy, urinary energy and methane energy losses were not affected $(\mathrm{P}>0.05)$ due to feeding of harad, ajwain, soapnut and garlic to buffaloes. Neeti (2017) also reported similar results with no effect of feeding a mixture of seven herbal additives on the energy balance of buffalo calves. In the present study, the losses in the form of methane were similar in all the groups. In contrast, Patra et al., (2010) observed about $24 \%$ reduction in methane production $(1 / \mathrm{kg}$ DDMI) in sheep fed on the diet supplemented with harad, whereas, this reduction was $23.6 \%$ in the sheep fed on diet supplemented with the mixture of harad and garlic resulting in decrease in methane energy loss as per cent of digestible energy intake by $20 \%$ in harad fed group and $24.8 \%$ in mix fed sheep. Yuan et al., (2007) reported that the addition of tea saponin@ $5 \mathrm{~g} / \mathrm{kg}$ DM and tea saponin plus disodium fumarate@20 g/kg DM resulted in decreased methane emissions by 8.5 and $9.6 \%$, respectively in sheep. Lotus pedunculatus having condensed tannins, when fed to lamb, showed 16\% reduction in methane production (Waghorn et al., 2003). Samal (2016) also reported faecal energy, urinary energy and methane energy loss were not affected by feeding feed additives containing PSM in male buffalo calves. The performance indices like feed intake and digestibility of nutrients were similar in the animals of all the three groups Table 3. 
Table.1 Chemical Composition (\% DM) of wheat straw and concentrate mixture and ajwain fed to male buffaloes

\begin{tabular}{|l|c|c|c|}
\hline Attributes & Concentrate & Wheat straw & Ajwain \\
\hline Organic matter & 91.3 & 92.4 & 87.25 \\
\hline Crude protein & 15.8 & 2.53 & 14.9 \\
\hline Ether extract & 3.43 & 1.24 & 2.65 \\
\hline Neutral detergent fibre & 40.37 & 84.45 & 32.2 \\
\hline Acid detergent fibre & 9.54 & 44.15 & 28.5 \\
\hline Ash & 8.7 & 7.56 & 12.75 \\
\hline
\end{tabular}

Table.2 Effect of feeding Ajwain on energy utilization of buffalo calves

\begin{tabular}{|l|l|l|l|l|l|}
\hline Attributes & T1 & T2 & T3 & SEM & P value \\
\hline GE Intake (Mcal/d) & $20.32 \pm 0.24$ & $19.66 \pm 0.46$ & $20.6 \pm 0.21$ & 0.2 & 0.149 \\
\hline FE loss (Mcal/d) & $6.47 \pm 0.22$ & $5.93 \pm 0.81$ & $6.56 \pm 0.55$ & 0.32 & 0.717 \\
\hline DE (Mcal/d) & $13.85 \pm 0.26$ & $13.73 \pm 0.72$ & $14.04 \pm 0.4$ & 0.27 & 0.904 \\
\hline UE loss (Mcal/d) & $1.81 \pm 0.11$ & $1.82 \pm 0.12$ & $1.64 \pm 0.11$ & 0.06 & 0.454 \\
\hline Methane loss (Mcal/d) & $1.34 \pm 0.04$ & $1.27 \pm 0.05$ & $1.2 \pm 0.05$ & 0.03 & 0.166 \\
\hline Methane loss as \% of GEI & $6.6 \pm 0.2$ & $6.44 \pm 0.26$ & $5.85 \pm 0.23$ & 0.15 & 0.086 \\
\hline ME (Mcal/d) & $10.69 \pm 0.36$ & $10.64 \pm 0.82$ & $11.2 \pm 0.49$ & 0.32 & 0.768 \\
\hline ME as \% of GE & $52.62 \pm 1.59$ & $54.21 \pm 4.05$ & $54.45 \pm 2.83$ & 1.62 & 0.896 \\
\hline HP (Mcal/d) & $8.63 \pm 0.27$ & $8.56 \pm 0.5$ & $8.25 \pm 0.33$ & 0.20 & 0.762 \\
\hline NE (Mcal/d) & $2.01 \pm 0.46$ & $2.35 \pm 0.51$ & $2.48 \pm 0.33$ & 0.24 & 0.745 \\
\hline
\end{tabular}

Table.3 Effect of ajwain feeding on growth performance in male buffaloes

\begin{tabular}{|l|c|c|c|c|c|}
\hline Attributes & $\mathbf{T}_{\mathbf{1}}$ & $\mathbf{T}_{\mathbf{2}}$ & $\mathbf{T}_{\mathbf{3}}$ & $\mathbf{S E M}$ & P value \\
\hline Intake, body weight change & and $\boldsymbol{F C}$ C & & & & \\
\hline Initial BW (kg) & 257.9 & 259.2 & 265.0 & 8.53 & 0.945 \\
\hline Final BW (kg) & 270.9 & 272.3 & 279.4 & 8.30 & 0.917 \\
\hline Body weight gain (g/day) & 433.3 & 436.6 & 479.9 & 17.44 & 0.510 \\
\hline Concentrate (kg/d) & 3.09 & 3.05 & 3.11 & 0.01 & 0.273 \\
\hline WS (kg/d) & 2.55 & 2.68 & 2.53 & 0.03 & 0.106 \\
\hline TDMI (kg) & 5.64 & 5.73 & 5.64 & 0.03 & 0.372 \\
\hline FCR & 13.17 & 12.76 & 11.39 & 0.55 & 0.410 \\
\hline
\end{tabular}


Statistically the body weight was also similar in all the three groups, however, there was $10.75 \%$ more weight gain in the animals of T3 where ajwain was fed @ of 2 of DMI resulting $13.51 \%$ improvement in FCR of T3 group. Non significant improvement in the performance of the animals of T3 group might be due to less number of animals in each group so the differences among the groups could not reach up to the significance level. Similar findings were also reported by Kumar et al., (2011), Pawar (2012), Vakili et al., (2013) with no effect on DMI, ADG and FCR after dietary supplementation of plant parts or their byproduct as additive in buffaloes. Santosa et al., (2015) reported no change in daily weight gain in dairy calves by feeding essential oils supplemented diet.

The above discussion indicating myriad of response by the animals to the feeding of EOs. which may find their explanation in factors like type, dose, combinations of EOs and also the breed and physiological stage of the animal. However, with the results of the present study it can be concluded that the feeding ajwain seeds, @ 1 and 2\% DMI respectively, did not have a significant effect on the net energy for weight gain in buffaloes.

\section{Acknowledgement}

The financial assistance provided to author in the form of Junior Research Fellowship and research grant provided by ICAR are gratefully acknowledged.

\section{References}

Brouwer, E., 1965. Report of sub-committee on constants and factors. In: Symposium of Energy Metabolism Held at European Association for Animal Production. Academic, London, Pp. 441-443.

Castillejos, L., Calsamiglia, S. and Ferret, A.
2006. Effect of essential oil active compounds on rumen microbial fermentation and nutrient flow in in vitro systems. Journal of Dairy Science 89(7): 2649-2658.

ICAR 2013. Nutrients requirements of cattle and buffalo, Indian Council of Agricultural Research, New Delhi.

Kumar, R., Kamra, D.N., Agarwal, N. and Chaudhary, L.C. 2011. Effect of feeding a mixture of plants containing secondary metabolites and peppermint oil on rumen fermentation, microbial profile and nutrient utilization in buffaloes. Indian Journal Animal Science 81 (5): 488-492.

Lakhani, N., Kamra, D.N. 2019 Immune status and haemato-biochemical profile of buffalo calves supplemented with phytogenic feed additives rich in tannins, saponins and essential oils. Tropical Animal Health Production 51, 565-573 .

Patra, A.K., Kamra, D.N. and Agarwal, N. 2010. Effects of extracts of spices on rumen methanogenesis, enzyme activities and fermentation of feeds in vitro. Journal Scientific Food Agriculture 90: 511-520.

Pawar, M.M. 2012. Assessment of essential oils as rumen modifiers and their effect on feed conversion efficiency in buffaloes, Ph.D. Thesis, Deemed University, Indian Veterinary Research Institute, Izatnagar, India

Samal, L., Chaudhary, L.C., Agarwal, N. and Kamra, D.N. 2016. Effects of plants containing secondary metabolites as feed additives on rumen metabolites and methanogen diversity of buffaloes. Animal Production Science 56(3):472481.

Santos F. H. R., De Paula M. R., Lezier D., Silva J. T., Santos G. and Bittar C. M. M. 2015. Essential oils for dairy calves: effects on performance, scours, rumen 
fermentation and intestinal fauna. Animal 9: 958-965.

SPSS. 2010. Statistical packages for Social Sciences, Version 20, SPSS Inc., Illinois, USA.

Vakili, A.R., Khorrami, B., Mesgaran, M.D. and Parand, E. 2013. The Effects of Thyme and Cinnamon Essential Oils on Performance, Rumen Fermentation and Blood Metabolites in Holstein Calves Consuming High Concentrate Diet. Asian Australasian Journal of Animal Science 26:935-944

Van Soest, P.V., Robertson, J.B. and Lewis, B.A., 1991. Methods for dietary fiber, neutral detergent fiber, and nonstarch polysaccharides in relation to animal nutrition. Journal Of Dairy Science. 74(10): 3583-3597.

Waghorn, G.C. and McNabb, W.C. 2003. Consequences of plant phenolic compounds for productivity and health of ruminants. Proceedings of the Nutrition Society 62(2): 383-392.

Yang, W.Z., Benchaar, C., Ametaj, B.N., Chaves, A.V., He, M.L. and McAllister, T.A. 2007. Effects of garlic and juniper berry essential oil on ruminal fermentation and on the site and extent of digestion in lactating cows. Journal of Dairy Science 90: 5671- 5681.

\section{How to cite this article:}

Kundan Kumar, V. B. Chaturvedi, Vipin and Pramod Kumar Soni. 2020. Energy Partitioning and Performance of Male Buffalo Calves Fed Ajwain Seed (Trachyspermum ammi) as Feed Additive. Int.J.Curr.Microbiol.App.Sci. 9(04): 1977-1982.

doi: https://doi.org/10.20546/ijcmas.2020.904.236 